\title{
Analysis on Inherent Characteristics and Behavior of Recycling Dust in Freeboard of COREX Melter Gasifier
}

\author{
Kaiping DU, ${ }^{*}$ Shengli WU, ${ }^{*}$ Zhekai ZHANG, Feng CHANG and Xinliang LIU \\ School of Metallurgical and Ecological Engineering, University of Science and Technology Beijing, Beijing, 100083 China. \\ (Received on July 24, 2014; accepted on September 2, 2014)
}

\begin{abstract}
The generator gas of melter gasifier inevitably carries a lot of dust, which would be transported to the freeboard for recycling, as a result of the existence of the fluidized bed. The recycling dust, with an attractive concentration of $\mathrm{C}$ and $\mathrm{Fe}$, is considered as a useful secondary material, thus it is important to investigate the inherent characteristics and behavior of recycling dust in the freeboard. In the present work, the recycling dust characteristics are investigated through the granulometry, chemical, mineralogical and micro analysis. The recycling dust has an irregular shape and an uneven granulometric distribution with the following primary minerals: $\mathrm{Fe}, \mathrm{FeO}, \mathrm{SiO}_{2}, 2 \mathrm{CaO} \cdot \mathrm{SiO}_{2}$ and $2 \mathrm{CaO} \cdot \mathrm{Al}_{2} \mathrm{O}_{3} \cdot \mathrm{SiO}_{2}$. Furthermore, a threedimensional mathematical model at steady state is developed to describe the recycling dust combustion and the freeboard temperature distribution, which significantly influences the recycling dust behavior. The region of high temperature above $3000 \mathrm{~K}$ can be observed in front of $\mathrm{DB}$ due to the combustion of $\mathrm{C}$ in the recycling dust, with a combustion ratio of almost $100 \%$. Based on the above analysis, the recycling dust behavior is complex. Fe and $\mathrm{FeO}$ in the recycling dust may be oxidized and finally smelts into liquid iron, while other minerals smelt into molten slag. It is worth noting that the phenomena of circulation and accumulation of alkali metals, $\mathrm{ZnO}$ and $\mathrm{S}$ could occur, despite that most of them are discharged out of the melter gasifier through the generator gas and molten slag.
\end{abstract}

KEY WORDS: recycling dust; inherent characteristics; behavior; freeboard; mathematical model.

\section{Introduction}

The COREX process, which has been the successfully applied in industrial scale production in South Africa, South Korea, India and China, is one of the most promising alternative ironmaking processes independent from coking coal while capable of meeting the environmental requirements. ${ }^{1-3)}$ The most innovative characteristic of COREX process is that all metallurgical work is carried out in two separate process reactors, namely pre-reduction shaft furnace and melter gasifier. The pre-reduction shaft furnace is placed above the melter gasifier to facilitate the gravity-induced descent of the material. ${ }^{4,5)}$ According to the physical state of the burden mixture and the different conditions of the chemical reactions, the melter gasifier, as shown in Fig. 1, could be divided into five zones from bottom to top, which are hearth, raceway, moving bed, fluidized bed and freeboard respectively. ${ }^{6-13)}$

Due to the existence of the fluidized bed, the generator gas of melter gasifier inevitably carries a lot of dust. The generator gas enters 4 hot gas cyclones for dedusting. Then the dust separated from the generator gas is transported by the conveying gas (nitrogen) to the freeboard for recycling. 4 dust burners (DB) and 6 oxygen burners (OB) are installed in the bottom of freeboard to convey recycling dust and oxy-

* Corresponding author: E-mail: dukaiping@gmail.com, wushengli@ustb.edu.cn

DOI: http://dx.doi.org/10.2355/isijinternational.54.2737 gen. Practical production shows that the recycling dust contains a considerable amount of carbon. The combustion of the carbon in the recycling dust with oxygen releases a large amount of heat that will impact the freeboard temperature, which should be maintained within a certain range. An inadequate freeboard temperature would lead to the issue that the hydrocarbons in the coal could not crack completely and the tar generates to block the generator gas nozzle, while an

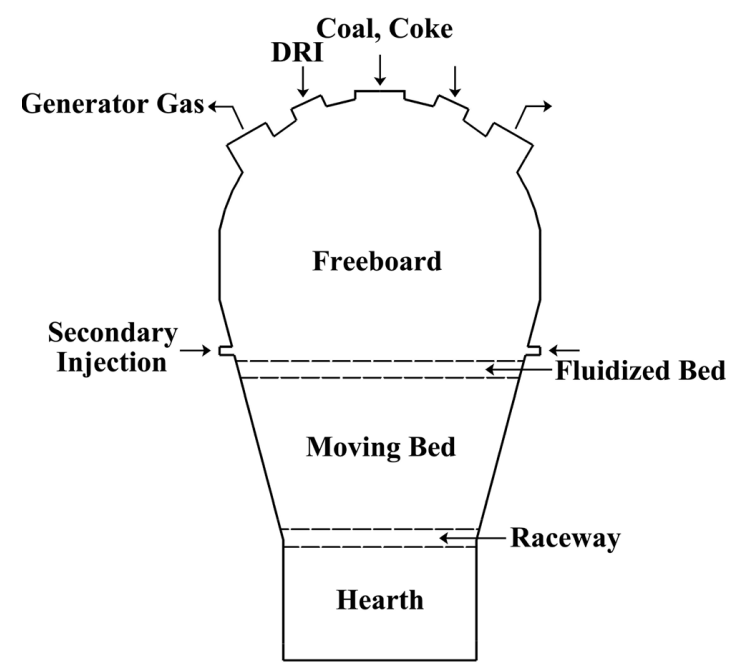

Fig. 1. Schematic diagram of COREX melter gasifier. 
excessive freeboard temperature may result in the burnout of the refractory and the device in the freeboard, especially the distribution system. In addition, the dust in the generator gas with higher temperature would soften and bond together to block the generator gas nozzle. Practical production shows that the generator gas temperature should be kept from $1303 \mathrm{~K}$ to $1363 \mathrm{~K}$.

Therefore, the freeboard is an important region in COREX melter gasifier. Sun et al. ${ }^{14)}$ analyzed the influence of operation parameters on the generator gas temperature through statistical and theoretical calculation. Liu et al. ${ }^{15)}$ developed a one-dimensional model to analyze the devolatilization of lump coal falling in the freeboard. However, the recycling dust combustion in the freeboard could not be derived from their works. Berger et al. ${ }^{16)}$ investigated the recycling dust combustion in front of DB by using different numerical approaches. However, the calculated generator gas temperature was $1174 \mathrm{~K}$, which was significantly lower than the measured data. Sun et al. ${ }^{17)}$ simulated the freeboard temperature fields under the conditions of fully open OBs and fully closed OBs by introducing a three-dimensional model ignoring the drag force of particles. However, the calculated results proved to be unsatisfactory as a result of the poor mesh quality. As can be seen from the above introduction, the work related to the inherent characteristics and behavior of recycling dust in the freeboard is limited.

Firstly, the recycling dust characteristics, including particle size distribution, chemical composition, mineralogical composition and morphology, are analyzed in the present work. These data will be applied to the mathematical model. Secondly, a modified three-dimensional mathematical model at steady state, which takes the drag force of particles and the turbulence model into consideration, is developed to describe the recycling dust combustion. The inner characteristics of the freeboard, especially the temperature distribution, are also analyzed. Thirdly, based on the recycling dust characteristics and the freeboard temperature distribution, the recycling dust behavior is further discussed.

\section{Analysis on Inherent Characteristics of Recycling Dust}

The recycling dust was sampled from COREX-3000, the largest plant with a design production capacity of 1.5 million tons of hot metal per year, in China. As a preparation step, it was dried for $4 \mathrm{~h}$ at $378 \mathrm{~K}$ and stored in a desiccator. The recycling dust was characterized through granulometry analysis, chemical analysis, mineralogical analysis and micro analysis.

\subsection{Granulometry Analysis}

The particle size distribution of the recycling dust is shown in Fig. 2. It can be seen that the particle size distribution is heterogeneous with a range between 5.03 and $91.09 \mu \mathrm{m}$. The mean particle size of the recycling dust is $28.88 \mu \mathrm{m}$, which is larger than other typical steel plant metallurgical dusts, such as the sintering dust and the electric arc furnace dust, ${ }^{18,19)}$ and similar to the blast furnace dust. ${ }^{20)}$ Such an uneven granulometric distribution probably results from the following aspects. (1) The source of the recycling dust is complex. When the burden materials, including

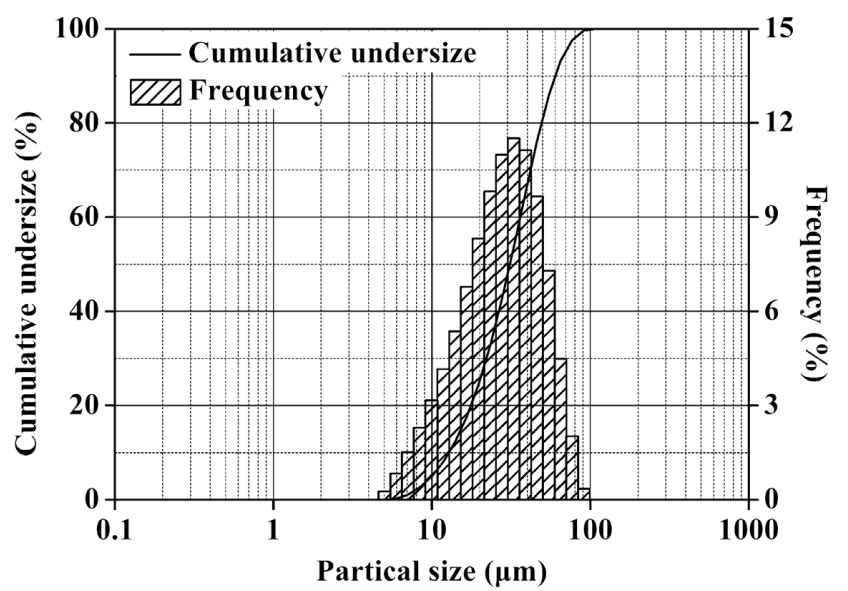

Fig. 2. Particle size distribution of recycling dust.

direct reduction iron (DRI) from the pre-reduction shaft furnace, lump ore and flux, falls onto the moving bed surface through the freeboard which is as high as $14 \mathrm{~m}$, part of the materials could breakup, and produce a lot of dust. On the other hand, along with the rapid heating process and gasification process of the lump coal in the moving bed, a lot of dust is generated by the thermal crack of lump coal. (2) Some smaller sized particles could agglomerate to form larger sized particles, which will be discussed later.

\subsection{Chemical Analysis}

The chemical analysis result of the recycling dust is presented in Table 1. The chemical composition of the recycling dust depends on its source, which has been discussed above. The main compositions include $\mathrm{C}, \mathrm{Fe}, \mathrm{CaO}, \mathrm{SiO}_{2}$, $\mathrm{Al}_{2} \mathrm{O}_{3}$ with a total mass fraction up to $90 \%$. Especially the sum of the total $\mathrm{C}$ and $\mathrm{Fe}$, which are useful elements in COREX process, is higher than $80 \%$, making recycling dust a valuable secondary material. Wasting of resources can be avoided by recycling these dusts. In addition, iron exists in the form of hematite, magnetite, wustite and metallic iron. However, since the DRI, the source of iron in the recycling dust, is composed of wustite and metallic iron, ${ }^{4,5)}$ the recycling dust only contain wustite and metallic iron. On the other hand, the reduction reaction condition of dust is relatively better in the generator gas pipe, considering the smaller particle diameter, the higher gas temperature and reduction potential that contribute to the reduction of wustite in the dust, which leads to the higher metallization ratio of the recycling dust.

\subsection{Mineralogical Analysis}

The mineralogical characterization of the recycling dust was performed by X-ray diffraction (XRD) analysis. The XRD pattern of the recycling dust is shown in Fig. 3. It can be seen that metallic iron $(\mathrm{Fe})$, wustite $(\mathrm{FeO})$, quartz $\left(\mathrm{SiO}_{2}\right)$, calcium silicate $\left(2 \mathrm{CaO} \cdot \mathrm{SiO}_{2}\right)$ and gehlenite $\left(2 \mathrm{CaO} \cdot \mathrm{Al}_{2} \mathrm{O}_{3} \cdot \mathrm{SiO}_{2}\right)$ are present in the recycling dust. It indicates that $\mathrm{SiO}_{2}$ could form three kinds of minerals in the recycling dust. Furthermore, since carbon from the lump coal exists in the form of amorphous carbon and other micro-composition, including $\mathrm{MgO}$, $\mathrm{MnO}$ and $\mathrm{ZnO}$, is relatively low in concentration, they could not be verified by XRD. 
Table 1. Chemical composition of recycling dust (mass fraction, \%).

\begin{tabular}{ccccccccccccc}
\hline $\mathrm{TC}$ & $\mathrm{TFe}$ & $\mathrm{MFe}$ & $\mathrm{CaO}$ & $\mathrm{SiO}_{2}$ & $\mathrm{MgO}$ & $\mathrm{Al}_{2} \mathrm{O}_{3}$ & $\mathrm{MnO}$ & $\mathrm{ZnO}$ & $\mathrm{K}_{2} \mathrm{O}$ & $\mathrm{Na}_{2} \mathrm{O}$ & $\mathrm{P}$ & $\mathrm{S}$ \\
\hline 35.00 & 47.10 & 42.45 & 4.70 & 5.40 & 1.40 & 3.20 & 0.10 & 0.01 & 0.39 & 0.10 & 0.04 & 0.99 \\
\hline
\end{tabular}

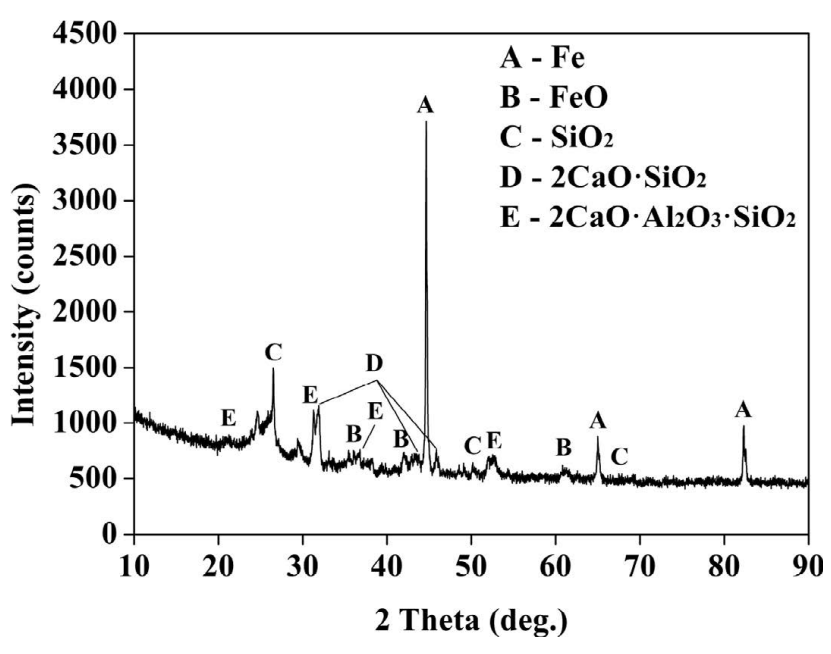

Fig. 3. XRD pattern of recycling dust.

\subsection{Micro Analysis}

Scanning electron microscopy (SEM) was used to gain further knowledge of the morphology and structure of the recycling dust. The scanning electron micrograph of recycling dust with a magnification of $500 \times$ is shown in Fig. 4. The shape of recycling dust appears irregular. The agglomeration between the smaller sized particles can be observed clearly. Through X-ray energy dispersive spectrometry (EDS), it can be seen that a large proportion of metallic iron, wustite and some gangue exist in the white agglomeration, and part of carbon is wrapped by metallic iron. In addition, the EDS analysis shows that the smooth, black particles are carbon from the lump coal.

\section{Analysis on Combustion of Recycling Dust}

A modified three-dimensional mathematical model at steady state is developed to analyze the recycling dust combustion. The diameter and chemical composition of recycling dust measured above are applied to this model. In addition, the freeboard temperature distribution is discussed in detail, which exerts a significant influence on the recycling dust behavior.

\subsection{Model Formulation}

3.1.1. Governing Equation and Chemical Reactions

The governing equations for the gas phase and particle phase are summarized in Table 2. The gas phase is treated as a continuum phase using the Eulerian method. The gas flow is solved by a set of three-dimensional steady state Reynolds averaged Navier-Stokes equations. The particle phase is treated as a dispersed phase using the Lagrangian method. The discrete particles trajectories are determined by the Newton's second law of motion without considering the interaction among particles. The drag force and the turbulence dispersion are considered in calculating the particle

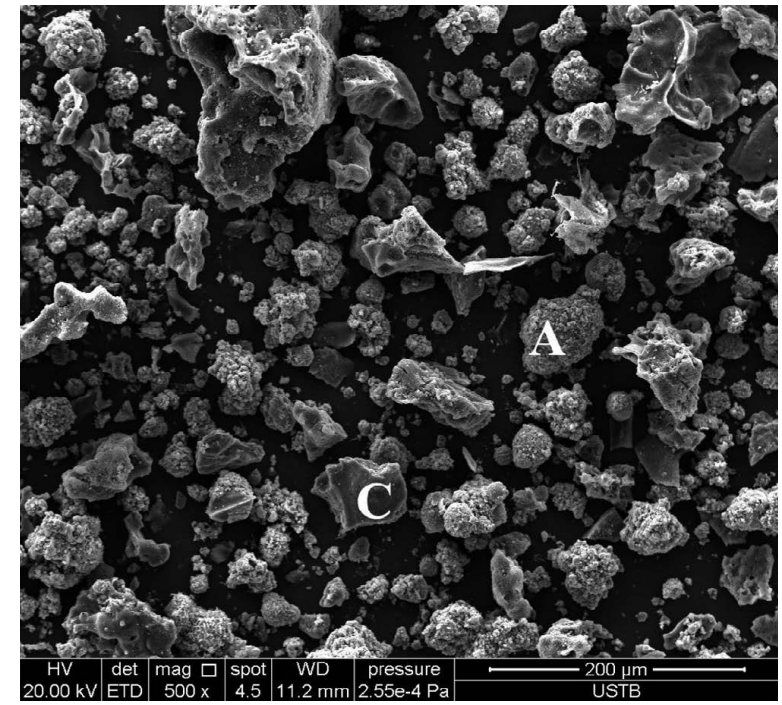

Fig. 4. Scanning electron micrograph (magnification $500 \times$ ) of recycling dust. Where: A: Agglomeration with metallic iron, wustite and some gangue, C: Carbon.

movement. In addition, the changes of gas and particle temperature are governed by three physical processes: convection heat transfer, radiative heat transfer and heat transfer associated with mass transfer.

The chemical reactions considered in this model are as listed in Table 3. The heterogeneous reactions, including carbon combustion, Boudouard reaction and water gas reaction, are calculated based on the multiple surface reaction model. ${ }^{23)}$ The eddy dissipation model ${ }^{24)}$ is used to simulate the homogeneous reactions, including the combustions of $\mathrm{CO}$ and $\mathrm{H}_{2}$. In order to simplify the model, other possible chemical reactions, including oxidation of $\mathrm{Fe}$ and $\mathrm{FeO}$, gangue melting and alkali metals gasification that will be discussed later, are not considered, because of their relatively lower heat release or absorption, reaction rate and oxygen consumption compared with the carbon combustion. Thus ignoring these reactions has little effect on the recycling dust combustion and freeboard temperature distribution.

\subsubsection{Numerical Model and Boundary Conditions}

The schematic diagram of the COREX melter gasifier freeboard is shown in Fig. 5, and the arrangement diagram of DB and OB is described in Fig. 6. The DBs and the OBs enter the freeboard with a $8^{\circ}$ angle to the horizontal. The DB is coaxial, with the recycling dust and the conveying gas (nitrogen) in the inner tube, and oxygen in the annular region. In addition, extra oxygen is fed through the OB. The typical plant operating parameters of COREX melter gasifier, as listed in Table $\mathbf{4}$, are used as the boundary conditions. As for the wall, the free-slip condition is applied at the wall boundary. At any point along the wall, the energy wall function is used to describe the wall heat loss. Besides, a zerogradient condition for all species is assumed at walls.

For computational convenience, the assumptions in this 
Table 2. Governing equations for gas and particle phases.

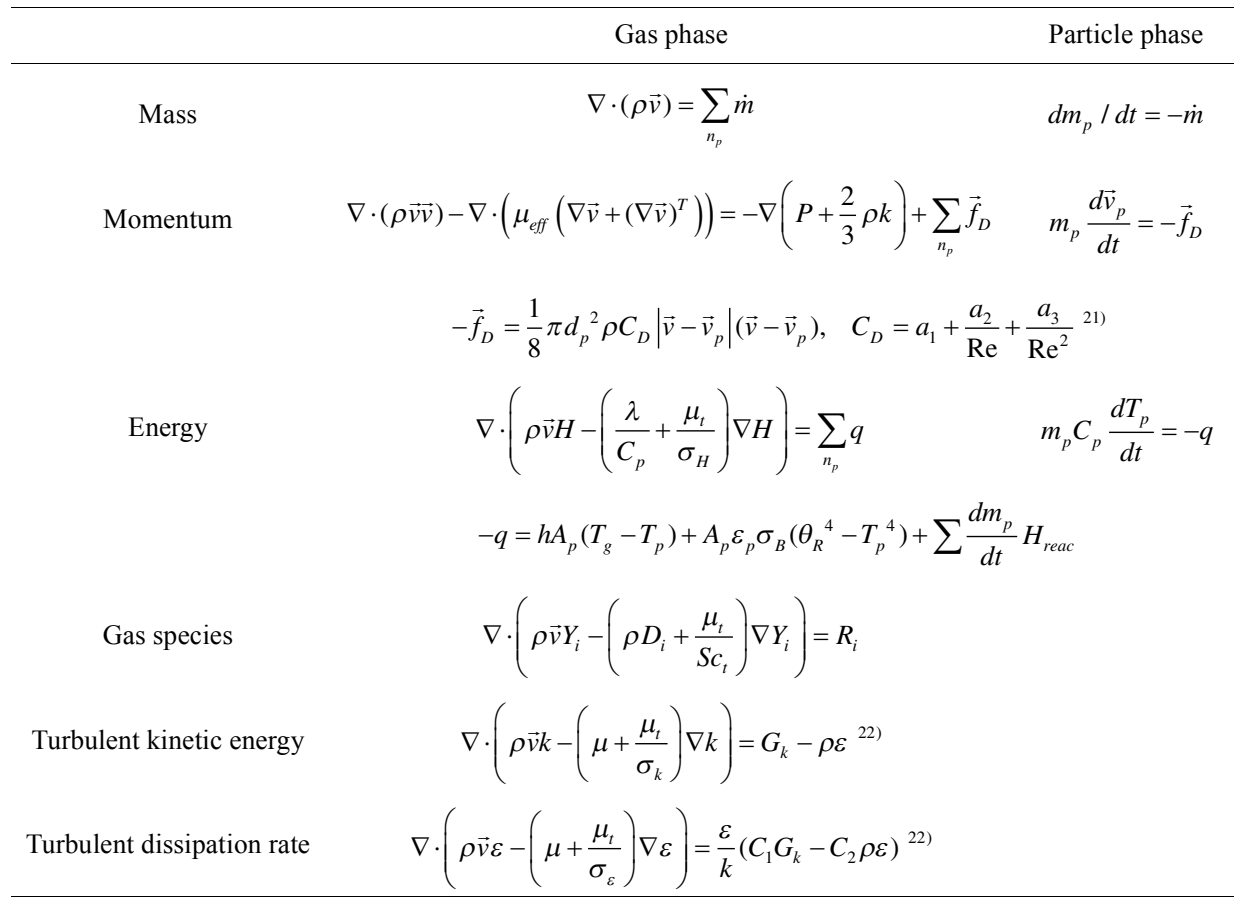

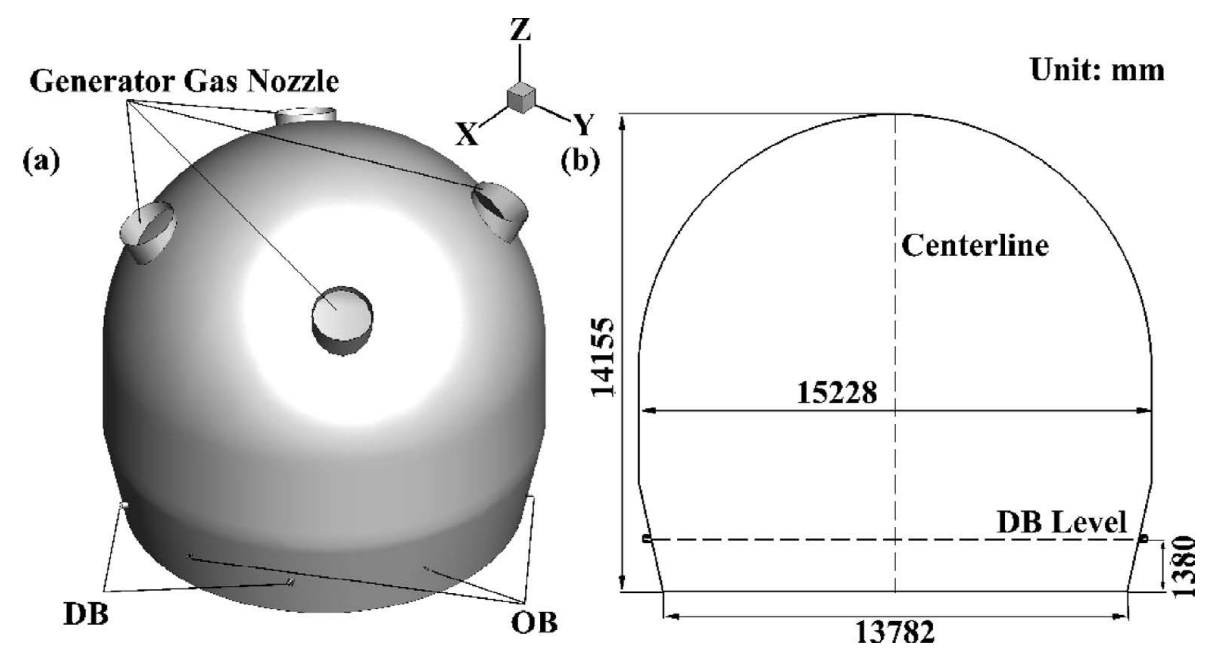

Fig. 5. Schematic diagram of COREX melter gasifier freeboard.

Table 3. Chemical reactions considered and their rates expressions.

\begin{tabular}{cc}
\hline Chemical reactions & Reaction rates expressions \\
\hline $\mathrm{C}+1 / 2 \mathrm{O}_{2} \rightarrow \mathrm{CO}$ & $\frac{d m_{p}}{d t}=\pi d_{p}{ }^{2} Y_{C, \text { Surf }} P_{i, \text { reac }} \frac{D_{i, \text { reac }} k_{c}}{D_{i, \text { reac }}+k_{c}}$ \\
$\mathrm{C}+\mathrm{CO}_{2} \rightarrow 2 \mathrm{CO}$ & $D_{i, \text { reac }}=\frac{D_{\text {ref }}\left(\frac{T_{p}+T_{g}}{d_{p}}\right)^{0.75}}{\mathrm{C}+\mathrm{H}_{2} \mathrm{O} \rightarrow \mathrm{CO}+\mathrm{H}_{2}}$ \\
\hline $\mathrm{CO}+1 / 2 \mathrm{O}_{2} \rightarrow \mathrm{CO}_{2}$ & $k_{c}=A_{c} \exp \left(-E / R T_{p}\right)$ \\
$\mathrm{H}_{2}+1 / 2 \mathrm{O}_{2} \rightarrow \mathrm{H}_{2} \mathrm{O}$ & $R_{i}=C_{A} \frac{\varepsilon}{k} \min \left(\frac{[i]}{v_{i}^{\prime}}\right)$ \\
\hline
\end{tabular}

model are given as below. (1) $\mathrm{CH}_{4}$, which is less than $3 \%$, is ignored, and hence, the gas species considered in this model include $\mathrm{CO}, \mathrm{CO}_{2}, \mathrm{H}_{2}, \mathrm{H}_{2} \mathrm{O}, \mathrm{N}_{2}$ and $\mathrm{O}_{2}$. (2) The composition, velocity and temperature of the reducing gas fed

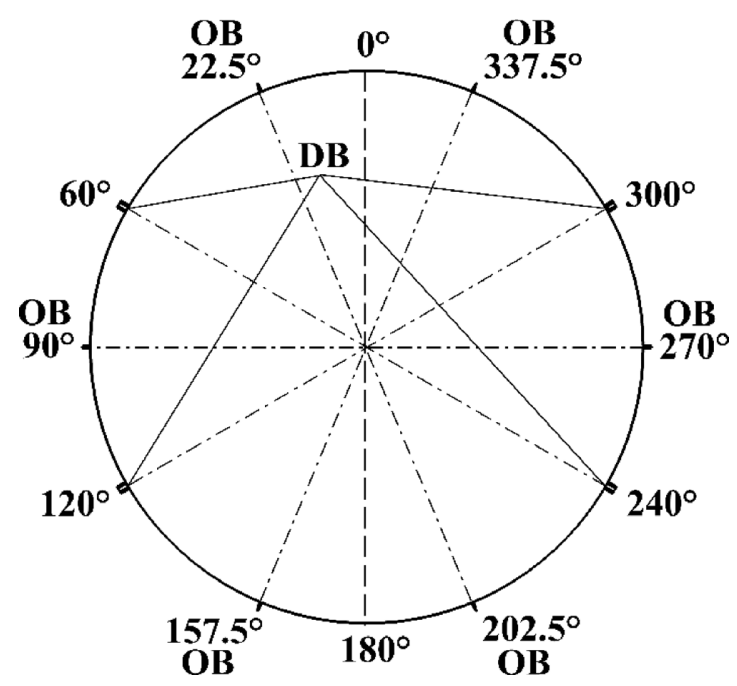

Fig. 6. Arrangement diagram of $\mathrm{DB}$ and $\mathrm{OB}$. 
Table 4. Operating parameters of COREX melter gasifier considered.

\begin{tabular}{lcr}
\hline \multicolumn{1}{c}{ Parameters } & \multicolumn{2}{c}{ Value } \\
\hline Recycling dust & $6900 \mathrm{~kg} / \mathrm{h}$ \\
Generator gas pressure & $350 \mathrm{kPa}$ & \\
Oxygen fed through OB & $4500 \mathrm{Nm}^{3} / \mathrm{h}$ & $298 \mathrm{~K}$ \\
Oxygen fed through DB & $18400 \mathrm{Nm}^{3} / \mathrm{h}$ & $298 \mathrm{~K}$ \\
Nitrogen fed through DB & $1200 \mathrm{Nm}^{3} / \mathrm{h}$ & $298 \mathrm{~K}$ \\
Reducing gas fed through moving bed & $0.45 \mathrm{~m} / \mathrm{s}$ & $1150 \mathrm{~K}$ \\
Reducing gas composition in volume fraction & & \\
\multicolumn{1}{c}{$\mathrm{CO}^{\mathrm{CO}}$} & $70.2 \%$ & \\
$\mathrm{CO}_{2}$ & $2.2 \%$ & \\
$\mathrm{H}_{2}$ & $22.6 \%$ & \\
$\mathrm{H}_{2} \mathrm{O}$ & $5.0 \%$ \\
\hline
\end{tabular}

through the moving bed are assumed to be uniform in the freeboard bottom, as listed in Table 4, and they are obtained from the mass and thermal balance calculations of COREX melter gasifier. ${ }^{16)}(3)$ The reducing gas fed through the moving bed is assumed to carry large amounts of fine carbon particles generated by the thermal crack of the lump coal, and these carbon particles will participate in Boudouard reaction and water gas reaction. ${ }^{16)}$ (4) Because it is impossible to directly measure the diameter and flow rate of carbon particle as a result of the harsh environment in the freeboard, the calculation condition of carbon particle is assumed to be the same as the data of Berger's work. ${ }^{16)}$ (5) The carbon particle and the recycling dust are assumed to be spherical and there is no break-up and coalescence. (6) Since the falling time of DRI, non-coking coal, silica and coke from the top of freeboard to the moving bed is very short, it has almost no effect on the characteristics inside freeboard. Thus, only the gas, the carbon particle and the recycling dust are considered.

The numerical technique is based on a three-dimensional, finite volume model. The total number of cells is 54260, and each cell represents a control volume. The differential equations are integrated directly in the control volume of the computational domain. The SIMPLE method for the relationship between velocity and pressure corrections and the first order upwind scheme for discretizing convection terms are applied in this model. ${ }^{25,26)}$

\subsection{Model Validation}

The mathematical model is validated in terms of the gas composition. In the present work, the generator gas composition including $\mathrm{CO}, \mathrm{CO}_{2}$ and $\mathrm{H}_{2}$ from the simulated results is compared with the plant operational data, as summarized in Table 5. Generally speaking, despite the moderate differences in the absolute values between measurement and simulation, the calculated gas volume fraction is basically consistent with the measured data, which proves the applicability of the present model for prediction of the recycling dust combustion and characteristics inside freeboard.

\subsection{General Features}

In order to fully understand the characteristics inside the
Table 5. Comparisons of generator gas composition in volume fraction including $\mathrm{CO}, \mathrm{CO}_{2}$ and $\mathrm{H}_{2}$ between simulation and measurement.

\begin{tabular}{ccccc}
\hline & Measured results & Simulated results & \multicolumn{2}{c}{ Absolute Error } \\
\hline $\mathrm{CO}$ & $62.8 \%$ & $64.4 \%$ & $1.6 \%$ & $2.5 \%$ \\
$\mathrm{CO}_{2}$ & $10.6 \%$ & $10.5 \%$ & $0.1 \%$ & $0.9 \%$ \\
$\mathrm{H}_{2}$ & $18.8 \%$ & $19.0 \%$ & $0.2 \%$ & $1.1 \%$ \\
\hline
\end{tabular}

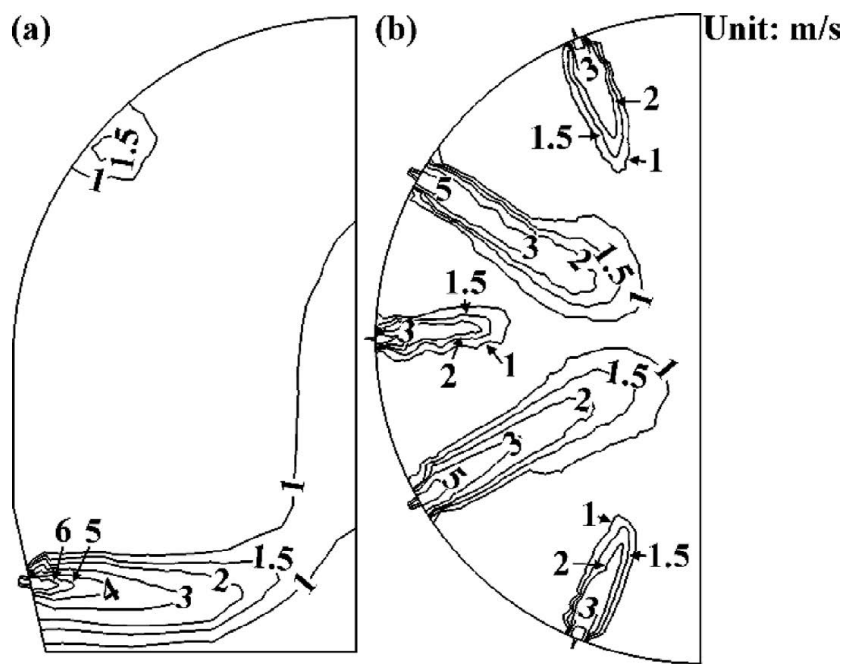

Fig. 7. Gas phase velocity distributions in (a) vertical plane and (b) horizontal plane.

freeboard in terms of the velocity, temperature, species distributions, the plane defined by centerlines of the DB and the freeboard (i.e., the vertical plane in Fig. 5(b)) and the plane determined by centerlines of the $\mathrm{DB}$ and the $\mathrm{OB}$ (i.e., the horizontal plane in Fig. 6) are selected respectively.

The gas phase velocity distributions in the vertical plane and the horizontal plane are shown in Fig. 7. It could be found that the gas stream forms a high speed jet, which gradually expands in the radial and axial direction, after exiting DB or OB. Due to the higher gas flow rate and the reaction of incomplete carbon combustion which increases gas volume, the region of the high speed jet in front of DB is larger than that in front of OB. In the central region of freeboard, the gas velocity gradually decreases to the value of about $1 \mathrm{~m} / \mathrm{s}$ as a result of the enlarged space. Around the generator gas nozzle, the gas velocity increases slightly owing to the relatively small diameter of the generator gas nozzle.

The gas phase temperature distributions in the vertical plane and the horizontal plane are described in Fig. 8. The region of high temperature more than $3000 \mathrm{~K}$ can be formed in front of DB due to the combustion of recycling dust. Furthermore, the carbon in the recycling dust has almost completely burned out in front of DB. Although the gas temperature in front of DB is almost equal to that in front of tuyere in the raceway, $\left.{ }^{9}\right)$ the gas flow circulation is not observed in front of $\mathrm{DB}$, thus the thermal damage probability of $\mathrm{DB}$ is much lower than that of tuyere. The high temperature region in front of $\mathrm{DB}$ is larger than that in front of $\mathrm{OB}$, which is consistent with the gas velocity field discussed above, as a result of the higher gas flow rate and the stronger 

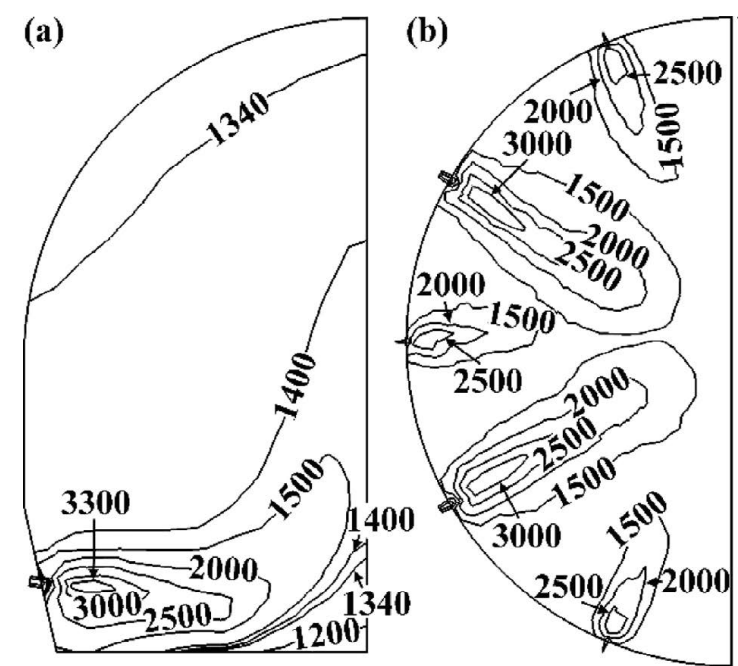

Fig. 8. Gas phase temperature distributions in (a) vertical plane and (b) horizontal plane.

combustion heat release. Furthermore, the gas temperature decreases slightly in the top region of the freeboard mainly on account of the wall heat transfer. In addition, the generator gas temperature is about $1338 \mathrm{~K}$, which meets practical production requirements.

The volume fraction distributions of gas species $(\mathrm{CO}$, $\mathrm{CO}_{2}, \mathrm{H}_{2}$ and $\left.\mathrm{H}_{2} \mathrm{O}\right)$ in the vertical plane are described in Fig. 9. Generally speaking, the volume fraction distribution of $\mathrm{CO}$ or $\mathrm{H}_{2}$ shows an opposite tendency to that of $\mathrm{CO}_{2}$ or $\mathrm{H}_{2} \mathrm{O}$ in the freeboard. Due to the combustion of recycling dust, $\mathrm{CO}$ and $\mathrm{H}_{2}$, the volume fraction of $\mathrm{CO}_{2}$ and $\mathrm{H}_{2} \mathrm{O}$ is highest, while that of $\mathrm{CO}$ and $\mathrm{H}_{2}$ is lowest in front of $\mathrm{DB}$, which is consistent with the gas temperature field. With the movement of gas, the volume fraction of $\mathrm{CO}_{2}$ and $\mathrm{H}_{2} \mathrm{O}$ gradually decreases on account of the dilution by the high volume fraction of $\mathrm{CO}$ and $\mathrm{H}_{2}$ in the reducing gas from the moving bed. Furthermore, in the upper part of freeboard, the volume fraction of $\mathrm{CO}$ and $\mathrm{H}_{2}$ in the peripheral region near the wall is higher than that in the central region. It can be analyzed that the weak combustion region, in which the gas temperature is lower than $1500 \mathrm{~K}$, exists between two burners. Part of reducing gas from the moving bed passes through these regions with weaker combustion to contribute to a higher volume fraction of $\mathrm{CO}$ and $\mathrm{H}_{2}$ near the wall.

Three variation trends could be observed in the radial distributions of the gas temperature and species along the DB level (refer to Fig. 5(b)) as shown in Fig. 10. Firstly, in front of $\mathrm{DB}$, the volume fraction of $\mathrm{N}_{2}$, which serves as the conveying gas of the recycling dust, rapidly decreases as a result of dilution by other gas species. Secondly, although the volume fractions of $\mathrm{CO}$ and $\mathrm{H}_{2}$ are lower in front of $\mathrm{DB}$, they gradually increase due to the rich contents of $\mathrm{CO}$ and $\mathrm{H}_{2}$ in the reducing gas from the moving bed. Thirdly, after that gas exits $\mathrm{DB}$, the volume fractions of $\mathrm{CO}_{2}, \mathrm{H}_{2} \mathrm{O}$ and gas temperature first increase and then decrease, under the combined effects of combustion and dilution as discussed above. In addition, since the DB has an inclination in relation to the horizontal and $\mathrm{O}_{2}$ is fed through the periphery region of the $\mathrm{DB}$, the volume fraction of $\mathrm{O}_{2}$ first increases and then decreases as well.
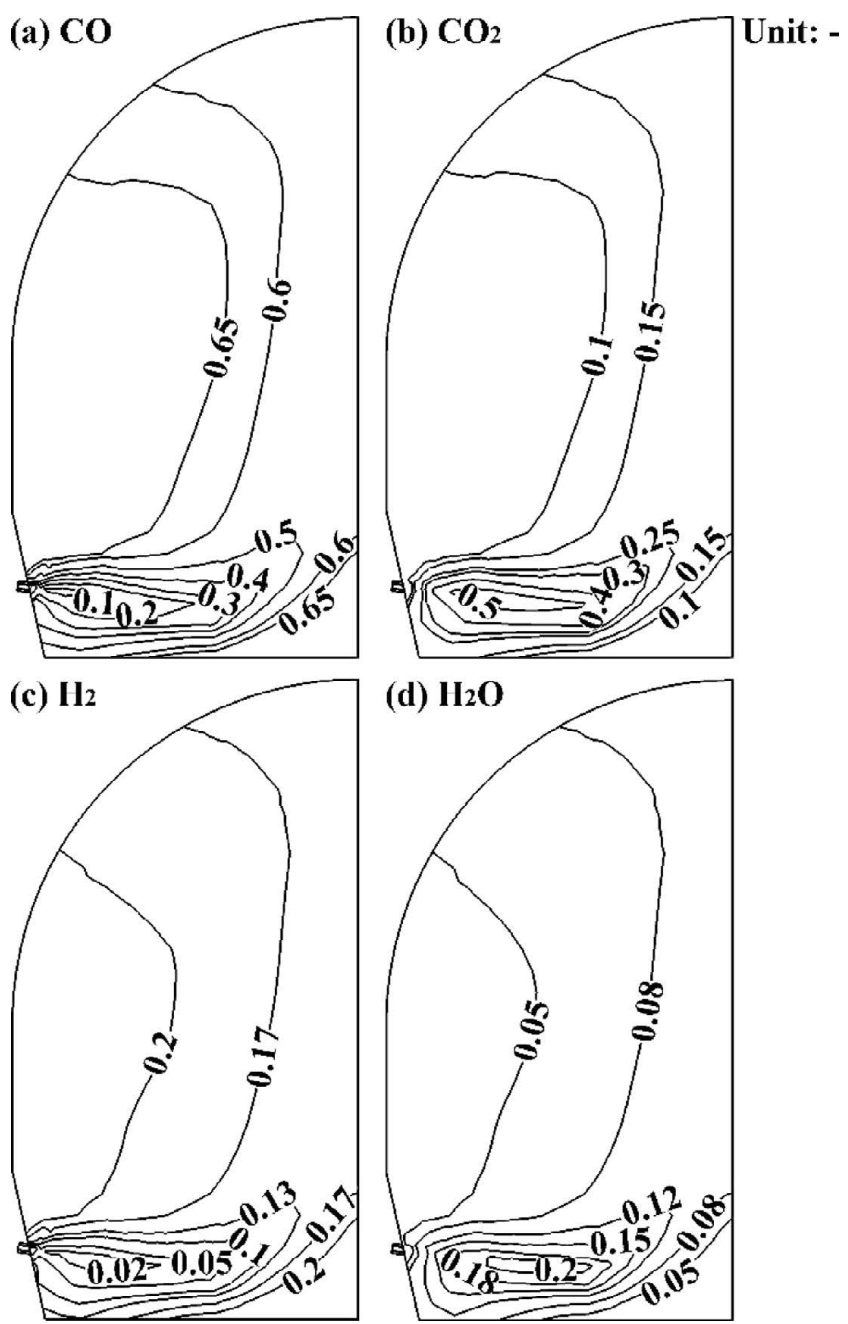

Fig. 9. Volume fraction distributions of gas species in vertical plane: (a) $\mathrm{CO}$, (b) $\mathrm{CO}_{2}$, (c) $\mathrm{H}_{2}$ and (d) $\mathrm{H}_{2} \mathrm{O}$.

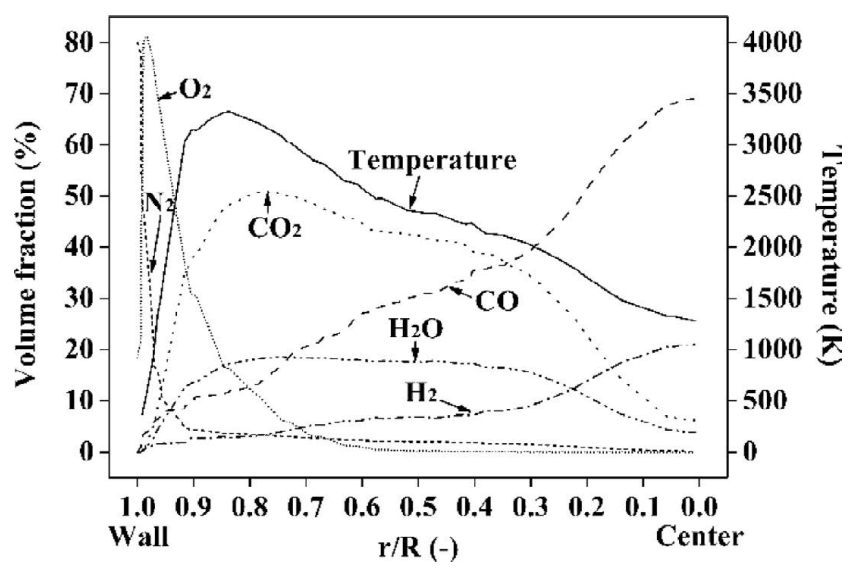

Fig. 10. Radial distributions of gas temperature and species along dust burner level.

\subsection{Effect of Flow Rate of Oxygen Fed through OB}

In actual production, due to the change in raw materials fed into the melter gasifier and production operations, the generator gas temperature may fluctuate, thus the flow rate of oxygen fed through $\mathrm{OB}$ should be adjusted to achieve a reasonable generator gas temperature. In this section, five oxygen flow rates, which varies from $4500 \mathrm{Nm}^{3} / \mathrm{h}$ (minimum flow rate) to $8100 \mathrm{Nm}^{3} / \mathrm{h}$ by a $900 \mathrm{Nm}^{3} / \mathrm{h}$ step, are 
selected.

The effect of flow rate of oxygen fed through OB on generator gas temperature is shown in Fig. 11. As oxygen flow rate increases from $4500 \mathrm{Nm}^{3} / \mathrm{h}$ to $8100 \mathrm{Nm}^{3} / \mathrm{h}$, the generator gas temperature rises by $41 \mathrm{~K}$. It is worth noting that when the oxygen flow is set at $7200 \mathrm{Nm}^{3} / \mathrm{h}$ or $8100 \mathrm{Nm}^{3} / \mathrm{h}$, the generator gas temperature reaches $1371 \mathrm{~K}$ or $1380 \mathrm{~K}$, exceeding the safe range (1303-1363 K), which may result in the refractory burnout and the generator gas nozzle blocking caused by the softening and bond of the dust. Therefore, under the current operating conditions, the flow rate of oxygen fed through OB should be controlled in the range less than $6300 \mathrm{Nm}^{3} / \mathrm{h}$.

The effect of flow rate of oxygen fed through OB on generator gas composition in volume fraction is summarized in Fig. 12. It can be seen that the volume fractions of $\mathrm{CO}$ and $\mathrm{H}_{2}$ increase by $1.23 \%$ and $0.51 \%$, while that of $\mathrm{CO}_{2}$ decreases by $1.23 \%$, when the flow rate of oxygen increases from $4500 \mathrm{Nm}^{3} / \mathrm{h}$ to $8100 \mathrm{Nm}^{3} / \mathrm{h}$. This phenomenon is basically consistent with the actual production, and results from the fact that the increasing freeboard temperature improves the rates of Boudouard reaction and water gas reaction, contrib-

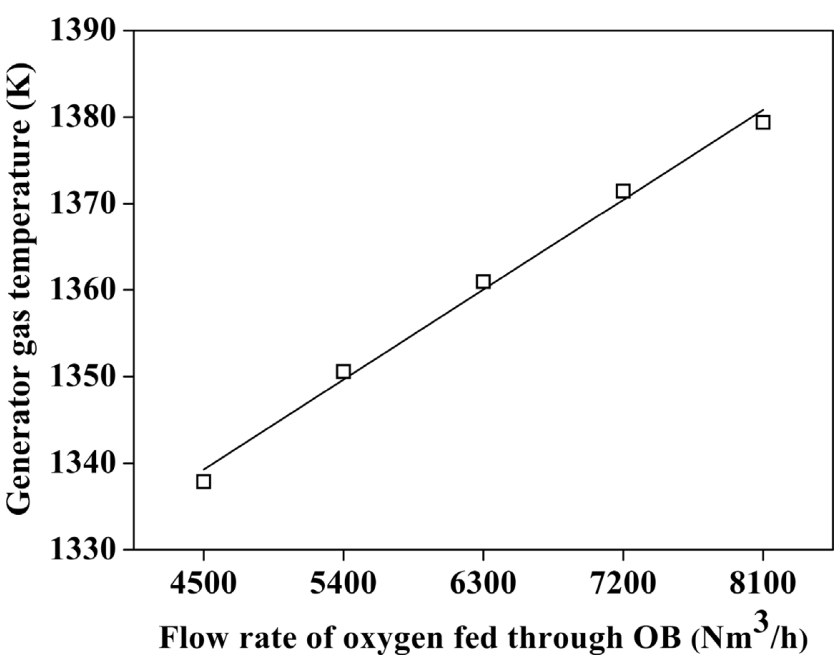

Fig. 11. Effect of flow rate of oxygen fed through OB on generator gas temperature.

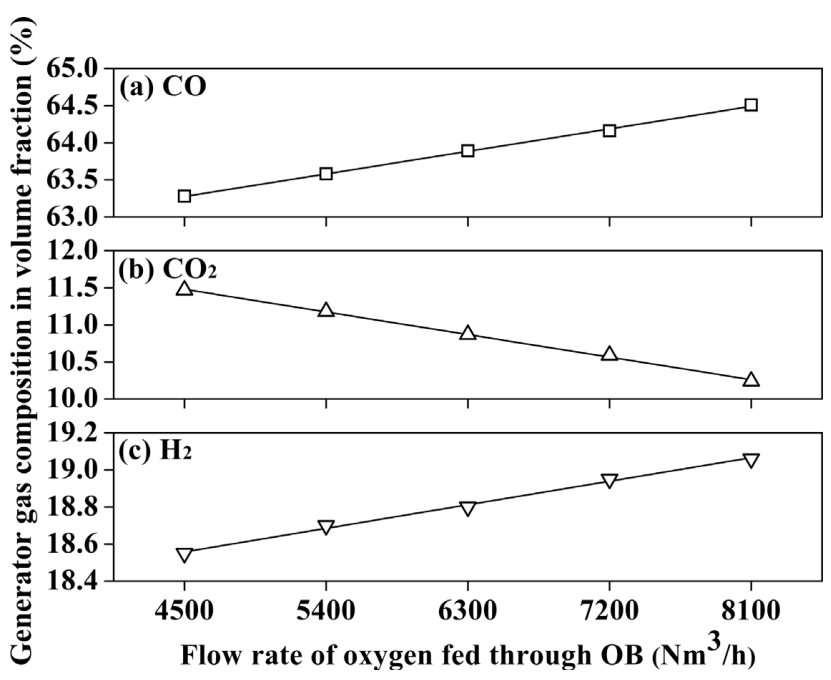

Fig. 12. Effect of flow rate of oxygen fed through OB on generator gas composition in volume fraction. uting to a greater amount of $\mathrm{CO}_{2}$ and $\mathrm{H}_{2} \mathrm{O}$ consumption.

Based on the above analysis, it could be concluded that the flow rate of oxygen has a positive relationship with the generator gas temperature, and a negative relationship with the volume fractions of $\mathrm{CO}_{2}$ in the generator gas. In actual production, the ironmaking professionals used to passively adjust the oxygen flow rate according to the generator gas temperature, ignoring the effects of oxygen flow rate on the generator gas composition. However, the generator gas in the melter gasifier would be conveyed into the shaft furnace to reduce the iron ore, and its higher volume fraction of $\mathrm{CO}_{2}$ would affect the reduction efficiency of the shaft furnace and decrease the metallization rate of DRI. Thus, it would result in an increasing reduction load of melter gasifier, which increases the fuel rate of melter gasifier. Therefore, in addition to generator gas temperature, the volume fraction of $\mathrm{CO}_{2}$ in generator gas should also be strictly controlled to allow for adjustment of the oxygen flow rate.

\section{Discussion on Behavior of Recycling Dust}

After being fed into the freeboard through DB, the recycling dust rapidly flows through the region of high temperature with more than $3000 \mathrm{~K}$, and the carbon in the recycling dust burned completely. However, the behaviors of other minerals in the recycling dust, including $\mathrm{Fe}, \mathrm{FeO}, \mathrm{SiO}_{2}$, $2 \mathrm{CaO} \cdot \mathrm{SiO}_{2}$ and $2 \mathrm{CaO} \cdot \mathrm{Al}_{2} \mathrm{O}_{3} \cdot \mathrm{SiO}_{2}$, are still not clear. Therefore, the behavior of recycling dust would be discussed based on the different minerals features as follows.

Due to the high volume fraction of $\mathrm{O}_{2}$ and the high temperature in front of $\mathrm{DB}, \mathrm{Fe}$ and $\mathrm{FeO}$ in the recycling dust may be oxidized to $\mathrm{Fe}_{3} \mathrm{O}_{4}$, even $\mathrm{Fe}_{2} \mathrm{O}_{3}$. Then the iron oxide rapidly softens, melts and forms liquid drops to drip into the moving bed, in which the iron oxide gradually smelts into liquid iron. According to the phase diagram of $\mathrm{Al}_{2} \mathrm{O}_{3}-\mathrm{CaO}-$ $\mathrm{SiO}_{2},{ }^{27)}$ the melting temperature of $\mathrm{SiO}_{2}, 2 \mathrm{CaO} \cdot \mathrm{SiO}_{2}$ and $2 \mathrm{CaO} \cdot \mathrm{Al}_{2} \mathrm{O}_{3} \cdot \mathrm{SiO}_{2}$ is $1998 \mathrm{~K}, 2403 \mathrm{~K}$ and $1863 \mathrm{~K}$ respectively, which is far lower than the temperature in front of $\mathrm{DB}$, thus these minerals also softens, melts and drips into the moving bed, in which they gradually smelts into molten slag, while a small amount of them smelts into liquid iron.

The alkali metals in the recycling dust immediately gasify and blend into the reducing gas, as a result of the high temperature above $3000 \mathrm{~K}$ in front of $\mathrm{DB}$. In the upper part of freeboard, since the gas temperature decreases, the alkali metals could be divided into four parts as shown in Fig. 13. Firstly, a part of alkali metals condense in the surface and pore of the burden materials. Along with the descending of the burden materials, some alkali metals gasify again in the raceway where the temperature is above $3500 \mathrm{~K}^{9-11)}$ and ascend with the reducing gas. In the low temperature region of moving bed, they either condense in the surface and pore of burden materials once more or pass into the freeboard with the reducing gas. While other alkali metals are absorbed by the molten slag and discharged out of the melter gasifier. Secondly, a part of alkali metals condense on the surface of dust which would be blown out of the freeboard. After being dedusted, they would be fed into the freeboard again. Thirdly, a part of alkali metals condense in the gap of the furnace lining, which will lead to the breakage and thickening of the furnace lining. Fourthly, a part of alkali 


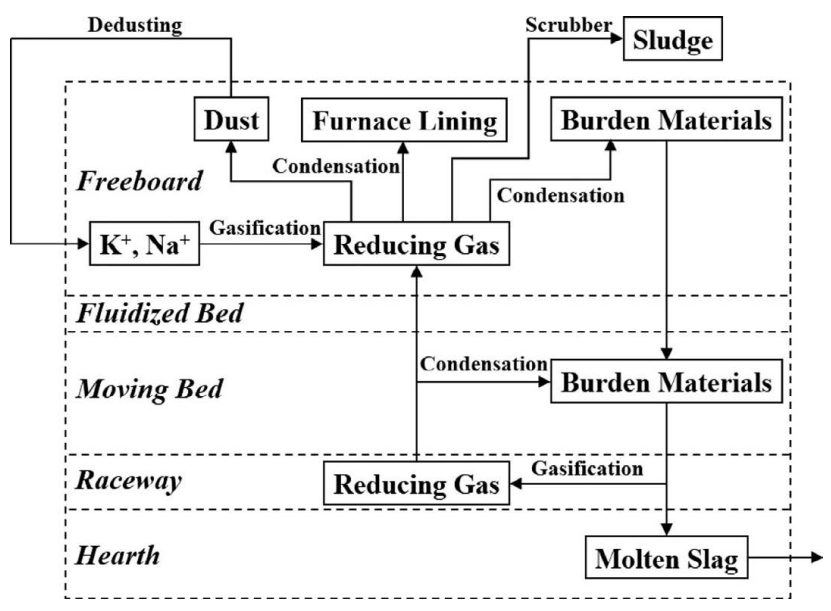

Fig. 13. Cycle diagram of alkali metals in melter gasifier.

metals will be discharged out of the freeboard through the generator gas, and gather in the sludge after the cold gas washing. Therefore, based on the above analysis, it can be seen that part of the alkali metals, carried by the recycling dust, is discharged out of the melter gasifier through the molten slag and the generator gas, while the remaining part of the alkali metals circulate in the melter gasifier.

The behaviors of $\mathrm{S}$ and $\mathrm{ZnO}$ in the recycling dust resemble those of alkali metals. Most of $\mathrm{S}$ is discharged out of the melter gasifier through molten slag, while most of $\mathrm{ZnO}$ is discharged through the generator gas. It is noted that the part of $\mathrm{ZnO}$ will condense in the furnace lining gap, which leads to thickening of the furnace lining. Certainly, part of $S$ and $\mathrm{ZnO}$ circulates by being absorbed by the dust blown into the freeboard. Furthermore, although the mineral structures of the micro-composition in the recycling dust, including $\mathrm{MgO}$ and $\mathrm{MnO}$ are not proven by $\mathrm{XRD}$, they finally smelt into molten slag, while a small amount of them smelts into liquid iron as in the case of $\mathrm{SiO}_{2}$.

Based on the above analysis, it could be concluded that the behaviors of different chemical composition in the recycling dust are complex. Especially the phenomena of circulation and accumulation could occur for the alkali metals, $\mathrm{S}$ and $\mathrm{ZnO}$. Their accumulation in the melter gasifier inevitably leads to many production problems, thus it is a meaningful topic as to whether the current practice of dust use is optimal. There might be a better way of effective utilization of melter gasifier dust containing much $\mathrm{C}$ and $\mathrm{Fe}$, just like blast furnace dust. This effective utilization will be further explored. Furthermore, these behaviors have been discussed merely based on the inherent characteristics of recycling dust and the simulated freeboard temperature distribution, the recycling dust behavior will be further verified in the future experimental investigation.

\section{Conclusions}

The inherent characteristics of recycling dust are obtained by using many techniques. The mean particle size of the recycling dust is $28.88 \mu \mathrm{m}$. The recycling dust has an irregular shape and an uneven granulometric distribution, which results from the complex source of the recycling dust and the agglomeration of the smaller sized particles. The prima- ry chemical composition of the recycling dust is $\mathrm{C}$ and $\mathrm{Fe}$ with a total mass fraction up to $80 \%$. Many minerals, including $\mathrm{Fe}, \mathrm{FeO}, \mathrm{SiO}_{2}, 2 \mathrm{CaO} \cdot \mathrm{SiO}_{2}$ and $2 \mathrm{CaO} \cdot \mathrm{Al}_{2} \mathrm{O}_{3} \cdot \mathrm{SiO}_{2}$, are detected in the recycling dust. A modified three-dimensional mathematical model at steady state is successfully developed to analyze the recycling dust combustion. As an important influence factor for the recycling dust behavior, the freeboard temperature distribution is also analyzed. The drag force of particles and the turbulence model are considered in this model. It can be seen that the combustion of $\mathrm{C}$ in the recycling dust mainly occurs in front of dust burner, with a combustion ratio of almost $100 \%$. Thus a region of high temperature more than $3000 \mathrm{~K}$ can be observed in front of DB. Under the present calculation conditions, the flow rate of oxygen fed through $\mathrm{OB}$ should be controlled within the range of less than $6300 \mathrm{Nm}^{3} / \mathrm{h}$ to prevent an excessive generator gas temperature. However, the decreasing oxygen flow rate results in a higher volume fraction of $\mathrm{CO}_{2}$, which would decrease the reduction efficiency of the shaft furnace and increase the fuel rate of melter gasifier. Therefore, in actual production, the suitable oxygen flow rate could be adjusted based on the generator gas temperature and composition. Furthermore, the recycling dust behavior is complex. Because of the high volume fraction of $\mathrm{O}_{2}$ and the high temperature in front of $\mathrm{DB}, \mathrm{Fe}$ and $\mathrm{FeO}$ in the recycling dust may be oxidized to $\mathrm{Fe}_{3} \mathrm{O}_{4}$, even $\mathrm{Fe}_{2} \mathrm{O}_{3}$, and finally smelts into liquid iron. While other minerals, including $\mathrm{SiO}_{2}, 2 \mathrm{CaO} \cdot \mathrm{SiO}_{2}, 2 \mathrm{CaO} \cdot \mathrm{Al}_{2} \mathrm{O}_{3} \cdot \mathrm{SiO}_{2}, \mathrm{MgO}$ and $\mathrm{MnO}$, finally smelt into molten slag. It is worth noting that the phenomena of circulation and accumulation of the alkali metals, $\mathrm{ZnO}$ and $\mathrm{S}$ could occur, despite that most of them are discharged out of the melter gasifier through the generator gas and molten slag. Thus a further exploration in effective utilization of melter gasifier dust is meaningful. In addition, these behaviors will be further verified in the future experimental investigation.

\section{Acknowledgement}

The authors would like to thank the financial support from the National Natural Science Foundation of China (No. U1260202) and Specialized Research Fund for Doctoral Program of Higher Education (No. 20120006110002). The authors are thankful for the linguistic corrections from Mr. Siming CHEN in this work.

\section{Nomenclature}

$A_{c}$ : Pre-exponential factors, -

$A_{p}$ : Particle area, $\mathrm{m}^{2}$

$a_{1}, a_{2}, a_{3}$ : Drag coefficient constants, -

$C_{1}, C_{2}$ : Turbulent model constants, -

$C_{A}$ : Empirical constant, -

$C_{D}$ : Drag coefficient, -

$C_{p}:$ Heat capacity, $\mathrm{J} / \mathrm{kg} \cdot \mathrm{K}$

$D_{i, \text { reac }}$ : Diffusion rate coefficient of the reactant gas phase species $i, \mathrm{~K}^{0.75} / \mathrm{m}$

$D_{i}$ : Mass diffusion coefficient of specie $i, \mathrm{~m}^{2} / \mathrm{s}$

$D_{\text {ref }}$ : Reference diffusivity, -

$d_{p}$ : Particle diameter, $\mathrm{m}$

$E$ : Activation energy, $\mathrm{J} / \mathrm{mol}$

$f_{D}$ : Drag force from a particle, $\mathrm{N}$

$G_{k}$ : Turbulence production due to viscous force, $\mathrm{kg} /$ 
$\mathrm{m} \cdot \mathrm{s}^{3}$

$H$ : Enthalpy, $\mathrm{J} / \mathrm{kg}$

$H_{\text {reac }}$ : Reaction heat, $\mathrm{J} / \mathrm{kg}$

$h$ : Heat transfer coefficient, $\mathrm{W} / \mathrm{m}^{2} \cdot \mathrm{K}$

$[i]$ : Molar concentration of reactant species $i, \mathrm{kmol} / \mathrm{m}^{3}$

$k$ : Turbulent kinetic energy, $\mathrm{m}^{2} / \mathrm{s}^{2}$

$k_{c}$ : Kinetic rate, -

$\dot{m}$ : Mass transfer rate from a particle, $\mathrm{kg} / \mathrm{s}$

$m_{p}:$ Mass of particle, $\mathrm{kg}$

$n_{p}$ : Particle number per unit volume, $\mathrm{m}^{-3}$

$P$ : Pressure, $\mathrm{Pa}$

$P_{i, \text { reac }}$ : Partial pressure of the reactant gas phase species $i, \mathrm{~Pa}$

$q$ : Heat transfer from a particle, $\mathrm{W}$

$R$ : Gas-law constant, $8.314472 \mathrm{~J} / \mathrm{mol} \cdot \mathrm{K}$

$R_{i}$ : Reaction rate of species $i, \mathrm{~kg} / \mathrm{m}^{3} \cdot \mathrm{s}$

Re: Reynolds number, -

$S c_{t}$ : Turbulent Schmidt number, -

$T_{g}$ : Gas temperature, $\mathrm{K}$

$T_{p}$ : Particle temperature, $\mathrm{K}$

$t$ : Time, $\mathrm{s}$

$\vec{v}$ : Velocity vector of gas, $\mathrm{m} / \mathrm{s}$

$\vec{v}_{p}$ : Velocity vector of particle, $\mathrm{m} / \mathrm{s}$

$Y_{i}$ : Mass fraction of species $i$,

$Y_{C \text {, Surf }}$ : Mass fraction of $\mathrm{C}$ in the particle surface, -

Greek letters

$\varepsilon$ : Turbulence dissipation rate, $\mathrm{m}^{2} / \mathrm{s}^{3}$

$\varepsilon_{p}$ : Particle emissivity, -

$\theta_{R}$ : Radiation temperature, $\mathrm{K}$

$\lambda$ : Thermal conductivity, $\mathrm{W} / \mathrm{m} \cdot \mathrm{K}$

$\rho$ : Density, $\mathrm{kg} / \mathrm{m}^{3}$

$\mu$ : Laminar viscosity, $\mathrm{Pa} \cdot \mathrm{s}$

$\mu_{t}$ : Turbulent viscosity, $\mathrm{Pa} \cdot \mathrm{s}$

$\sigma_{B}$ : Stefan-Boltzmann constant, $5.67 \times 10^{-8} \mathrm{~W} / \mathrm{m}^{2} \cdot \mathrm{K}^{4}$

$\sigma_{k}, \sigma_{\varepsilon}:$ Turbulence model constants, -

Abbreviations

DB: Dust burner

DRI: Direct reduction iron
EDS: X-ray energy dispersive spectrometry

OB: Oxygen burner

SEM: Scanning electron microscopy

XRD: X-ray diffraction

\section{REFERENCES}

1) H. M. W. Delport: Ironmaking Steelmaking, 19 (1992), 183.

2) P. P. Kumar, L. M. Garg and S. S. Gupta: Ironmaking Steelmaking, 33 (2006), 29.

3) X. Li: 3rd Baosteel Biennial Academic Conf., SSTLPH, Shanghai, (2008), A70

4) J. Xu, S. Wu, M. Kou and K. Du: ISIJ Int., 53 (2013), 576

5) S. Wu, K. Du, J. Xu, W. Shen, M. Kou and Z. Zhang: JOM, 66 (2014), 1265.

6) Z. Li, L. Guo, S. Wu and X. Chen: 3rd Baosteel Biennial Academic Conf., SSTLPH, Shanghai, (2008), A215.

7) J. Lin, Z. Kuang, H. Zhou and H. Xu: 4th Baosteel Biennial Academic Conf., SSTLPH, Shanghai, (2010), A69.

8) K. Du, S. Wu, M. Kou, W. Shen and Z. Zhang: Steel Res. Int., 85 (2014), 466.

9) K. Du, S. Wu, J. Xu, W. Shen and M. Kou: 6th Int. Cong. on the Science and Technology of Ironmaking, ABM, São Paulo, (2012), 382 .

10) Y. Qu, Z. Zou and Y. Xiao: ISIJ Int., 52 (2012), 2186.

11) S. Pal and A. K. Lahiri: Metall. Mater. Trans. B, 34B (2003), 103.

12) S. C. Lee, M. K. Shin, S. Joo and J. K. Yoon: ISIJ Int., 39 (1999), 319

13) S. C. Lee, M. K. Shin, S. Joo and J. K. Yoon: ISIJ Int., 40 (2000), 1073.

14) J. Sun, S. Wu, M. Kou, W. Shen and K. Du: ISIJ Int., 54 (2014), 43.

15) X. Liu, G. Pan, G. Wang and Z. Wen: Energ. Fuel., 25 (2011), 5729.

16) K. Berger, Ch. Weiss and W. L. Kepplinger: Steel Res. Int., 79 (2008), 579.

17) Y. Sun, Z. Di, H. Li, Z. Luo and Z. Zou: Adv. Mater. Res., 284-286 (2011), 1165.

18) C. Peng, Z. Guo and F. Zhang: ISIJ Int., 48 (2008), 1398.

19) M. C. da Silva, A. M. Bernardes, C. P. Bergmann, J. A. S. Tenório and D. C. R. Espinosa: Ironmaking Steelmaking, 35 (2008), 315.

20) J. Vereš, Š. Jakabský and M. Lovás: Acta Montan. Slovaca, 16 (2011), 185

21) S. A. Morsi and A. J. Alexander: J. Fluid Mech., 55 (1972), 193.

22) B. E. Launder and D. B. Spalding: Comput. Method. Appl. Mech. Eng., 3 (1974), 269.

23) I. M. Smith: 19th Symp. (Int.) on Combustion, The Combustion Institute, Pittsburgh, PA, (1982), 1045.

24) B. F. Magnussen and B. H. Hjertager: 16th Symp. Int. on Combustion, The Combustion Institute, Pittsburgh, PA, (1977), 719.

25) S. V. Patankar: Numerical Heat Transfer and Fluid Flow, Hemisphere, Washington D. C., (1980), 126.

26) J. D. Anderson: Computational Fluid Dynamics: the Basics with Application, Tsinghua University Press, Beijing, (2002), 179.

27) Slag Atlas, VDEh, Verlag Stahleisen Gmbh, Düsseldorf, (1995), 105. 